\title{
İstisnai Bir Uzaktan Eğitim-öğretim Deneyiminin Öğrettikleri
}

\section{Kevser Yıldırım}

\begin{abstract}
Özet
Bu yazıda, öncelikle Covid-19 acil uzaktan öğretim döneminin uzaktan eğitim ve çevrim içi öğrenmeyle farkları üzerinde durulmuştur. Daha sonra, bu dönemin değerlendirilmesinin önemi ve eğitimde bundan sonraki olası doğrultular (yüz yüze eğitimde teknolojiyi daha etkili kullanma, harmanlanmış eğitimi derslerin olağan parçası haline getirme ve acil bir durumda uzaktan eğitimögretime hazır olma) üzerinde durulmuştur. Son bölümde, teknoloji entegrasyonu, öğretmenin varlığı, sosyal varlık, otonomi, ters yüz öğrenme, harmanlanmış öğrenme, ders saatleri, mesleki gelişim, çevrim içi öğrenme toplulukları, ekran süreleri, dijital okuryazarlık, internet etiği, dijital bölünme, eğitimde eşitlik, evrensel tasarım, eleştiri-tartışma kültürü, eğitim teorisi-felsefesi gibi bu dönemde öne çıkan bazı hususlar irdelenmiş ve bu hususlarla ilgili öneriler sunulmuştur.
\end{abstract}

Anahtar kelimeler: acil uzaktan öğretim, covid-19, dijital bölünme, eşitlik, evrensel tasarım, koronavirüs, mesleki gelişim, uzaktan eğitim

\section{Lessons From an Exceptional Distance Education Experience}

\begin{abstract}
In this article, firstly, the differences of Covid-19 emergency remote teaching period with distance education and online learning are emphasized. Then, the importance of evaluating this period and possible future directions in education (using technology more effectively in face-to-face education, making blended education a regular part of the lessons and being ready for distance education in an emergency) are emphasized. In the last section, some prominent issues in this period such as technology integration, teacher presence, social presence, autonomy, flipped learning, blended learning, course hours, professional development, online learning communities, screen times, digital literacy, netiquette, digital divide, equality in education, universal design, culture of criticism and debate, educational theory-philosophy, have been examined and suggestions are made regarding these issues.
\end{abstract}

Keywords: coronavirus, covid-19, digital divide, distance education, emergency remote teaching, equality, professional development, universal design

1 Dr., Danışman, Yenidoğu Eğitim Kurumları, editorkevser@hotmail.com. ORCID: 0000-0003-2237-9739

Lisansını tarih, yüksek lisansını eğitim yönetimi ve denetimi, doktorasını eğitim teknolojisi alanında yapmıştır. Farklı kurumlarda öğretmenlik, editörlük, eğitim yöneticiliği gibi görevler yapmış olan Yıldırım, halihazırda Yenidoğu Eğitim Kurumlarında eğitim-araştırma danışmanlığı yapmakta ve eğitim teknolojisi, öğretmen eğitimi, araştırmacı öğretmenlik, çocuklarla araştırma, sosyal bilimlerde araştırma yöntemleri, eğitim araştırmaları felsefesi ve eğitim bilimleri felsefesi alanlarında bağımsız araştırmacı olarak çalışmaya devam etmektedir. Ayrıca, sosyal bilimler ve felsefe okumaları yoluyla, eğitim teorisi ve eğitim felsefesi üzerinde düşünmeye devam etmektedir.

\section{Derleme \\ Makalesi}

Review

Article

Başvuru/Submitted

4 Ağu/Aug 2020

Kabul/Accepted

7 Ağu/Aug 2020

Yayın/Published

10 Ağu/Aug 2020

Copyright@

ÖNCÜ 2020

Atıf/Cite: Yıldırım, K. (2020). İstisnai bir uzaktan eğitim-öğretim deneyiminin ögrettikleri. Alanyazın, 1(1), 7-15. doi:http:// dx.doi.org/10.22596/ cresjournal.0101.7.16 
Uzaktan eğitimin 1700’lü yıllarda mektupla eğitim süreciyle başladığı kabul edilir. Yüz yüze eğitime erişimde oluşan çeşitli zorluklar nedeniyle insanlar mektup yoluyla eğitime devam etmiş ve sertifika veya diplomalarını bu şekilde edinme yoluna gitmişlerdir. Uzaktan eğitim, iletişim teknolojilerindeki gelişmelere paralel olarak sırasıyla radyo, televizyon, bilgisayar ve internet temelli olarak yolculuğunu sürdürmüştür. İnternetin sürece dâhil olmasıyla beraber çevrim içi öğrenme kavramı da sıklıkla kullanılmaya başlanmıştır. Uzaktan eğitim ve çevrim içi öğrenme kavramlarının arasında farklılıklar olmasına rağmen, çevrim içi öğrenme uzaktan eğitimin "en yeni ve en popüler formu” (Stern, t.y.) olarak görüldüğü için, bu iki kavram zaman zaman birbirinin yerine kullanılmaktadır. "Uzaktan” ifadesi, mektupla başladığı ilk günden beri öğrenenlerle öğretenlerin ve kaynakların bir arada olmadığı, aynı zamanı veya mekânı paylaşmadığı bir eğitim biçimini ifade etmek için kullanılmaktadır (Bozkurt ve Sharma, 2020; Schlosser ve Simonson, 2009, s. 1'den akt., Simonson, Smaldino ve Zvacek, 2015). Çevrim içi öğrenme ise, "kısmen veya tamamen internet üzerinden gerçekleşen ögrrenme” (Means, Toyama, Murphy, Bakia ve Jones, 2010, s. 9.) olarak tanımlanmakta, geleneksel sınıf ortamındaki eğitimin internet üzerinden yürütülmesi olarak görülmektedir (Durdu ve Onay Durdu, 2013).

Mektupla başlayan uzaktan eğitimin ve internetle başlayan çevrim içi öğrenmenin yolculuğu ${ }^{1}$, Dünya çapında etkili olan Covid-19 pandemisiyle birlikte yeni bir dönemece girmiş, salgınla mücadele kapsamında okulların/üniversitelerin kapatılması yüzünden bir anda tüm yüz yüze eğitim çalışmaları uzaktan eğitime ve çoğunlukla çevrim içi öğrenmeye tahvil edilmiştir. Fakat uzaktan eğitim, "etkili bir öğrenme ekolojisi oluşturmak için dikkatli planlama, tasarım ve hedeflerin belirlenmesini gerektiren karmaşık bir süreçtir.” (Bozkurt ve Sharma, 2020). Pandemi sonrasında evlerine çekilen öğretmenlerin büyük çoğunluğunun uzaktan eğitim konusunda yeterli bilgi, deneyim ve zamanı olmadığı,

Günün sonunda adı nasıl

kabul görürse görsün,

yaşanılan bu süreç,

genelde eğitim tarihine

özelde eğitim teknolojisi

ve uzaktan eğitimin

tarihine istisnai bir

dönem olarak geçecek

gibi görünmektedir. çoğu durumda altyapı, cihaz, donanım ve yazilım eksiklikleri de olduğu için bu şartlarda sürdürülen uzaktan eğitim çalışmalarının tam tamına uzaktan eğitim sayılamayacağı öne sürülebilir. Ayrıca uzaktan eğitimde ayrı mekânlarda yaşayan bireylerin hem bilişsel hem de sosyal katılımını sağlamak için "farklı etkileşim türlerini destekleyen” bir öğrenme süreci oluşturmak önemlidir (Hodges, Moore, Lockee, Trust and Bond, 2020). Fakat hem yaşanan sürecin sosyal etkileri hem de çevrim içi derslerde etkileşimli bir tasarımı etkili bir

1 İnternet üzerinden yapılan uzaktan eğitim anlamında bazı kaynaklarda "çevrim içi uzaktan eğitim (online distance education)” ifadesi kullanılmaktadır. Bknz. Bozkurt ve Sharma, 2020. Ayrıca öğretmen etkinliğini vurgulamak için “çevrim içi öğretim (online teaching)" kavramı da kullanılmaktadır. Bknz. Cai ve Wang, 2020; Yen, 2020. 
şekilde yapacak deneyim ve zamana sahip olunmaması gibi nedenlerle bu açıdan da sürecin tam bir uzaktan eğitim süreci olmadığı söylenebilir. Uzaktan eğitim, öğretim teknolojisi vb. alanlar üzerine çalışan araştırmacılar bu dönemi, olağan koşullarda sürdürülen uzaktan eğitimden ayırmak için "acil uzaktan öğretim" (Hodges vd., 2020) $)^{2}$ şeklinde isimlendirmeyi önermektedir." Eğitim yerine "öğretim" kavramının vurgulanması ise acil gelişen bu sürecin daha çok öğretmenlerin sorumluluğu altında yürütülmesinden kaynaklanmaktadır (Hodges, 2020).

Günün sonunda $a d \imath$ nasıl kabul görürse görsün, yaşanılan bu süreç, genelde eğitim tarihine özelde eğitim teknolojisi ve uzaktan eğitimin tarihine istisnai bir dönem olarak geçecek gibi görünmektedir. Ve bu süreçte, tam anlamıyla uzaktan eğitimin veya çevrim içi öğrenmenin yapılamadığı kabul ediliyorsa (Bozkurt ve

Bu süreçte kazanılan deneyimlerin değerlendirilmesi, ilerleyen dönemlerde yüz yüze eğitimde teknolojiyi daha etkili kullanmak, yüz yüze-çevrim içi bir arada harmanlanmış eğitim çalışmalarını derslerin olağan parçası haline getirmek ve acil bir durumda uzaktan eğitim-öğretime hazır olmak şeklinde üç ana doğrultuda yapılabilir. Sharma, 2020; Golden, 2020; Hodges vd., 2020; Shisley, 2020; Yıldız ve Kartal, 2020) bile bugün gelinen noktada, öğretmenlerin uzaktan eğitim ve çevrim içi öğrenme için önemli deneyimler kazandığı söylenebilir (Shisley, 2020). Bu aşamada önemli olan bu deneyimlerin bundan sonraki süreçler için nasıl kullanılabileceğini etkili bir şekilde değerlendirmektir.

$2 \mathrm{Bu}$ dönemi ifade etmek için "acil uzaktan öğretim (emergency remote teaching)" kavramını kullanan farklı birkaç örnek olarak şu yayınlara bakılabilir: Bozkurt ve Sharma, 2020; Şen Akbulut, 2020; Yıldız ve Kartal, 2020.

3 Bu isimlendirme önerisi dışında Golden (2020) gibi "acil” yerine "geçici” kavramına vurgu yaparak, "geçici uzaktan ögrretim” demeyi tercih edenler de olmaktadır.

\section{COVID-19 CORONAVIRUS}
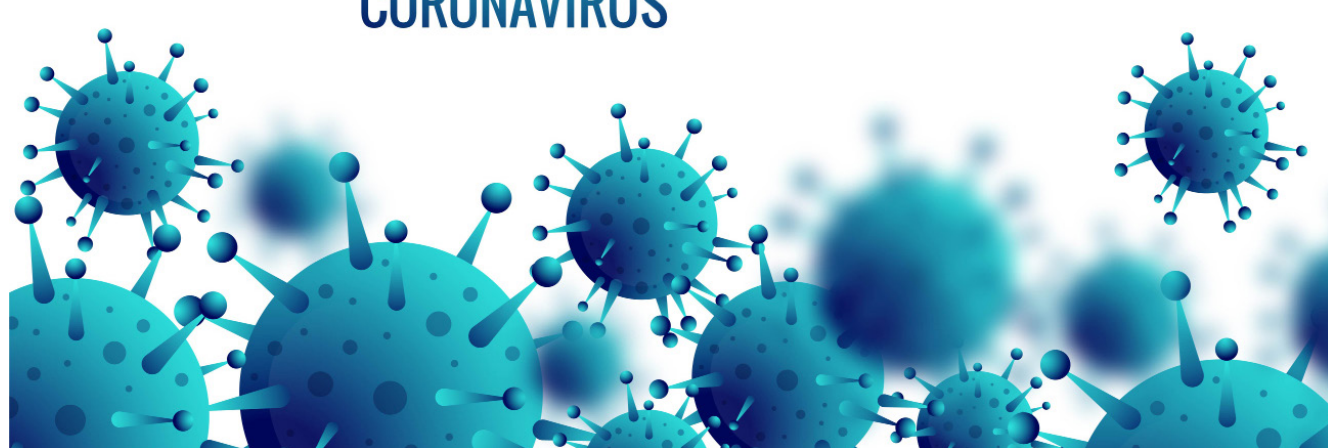
Bu değerlendirme önemlidir çünkü yaşanılan bu dönemde de daha önceki deneyimler işe koşulmuştur. Örneğin; bu süreç başlamadan önce teknoloji entegrasyonuna önem veren kurumların ve öğretmenlerin uzaktan eğitim sürecine adaptasyonunun daha kolay olduğu, bunun dışında yüz yüze eğitimin ve çevrim içi öğrenme ortamlarının beraber kullanıldığı harmanlanmış eğitimi deneyimlemiş öğretmenlerin veya sadece basit anlamda eğitimde teknolojiden faydalanma konusunda sınırlı da olsa deneyimi olan öğretmenlerin de sürece daha kolay uyum sağladığı söylenebilir. Süreç içerisinde yine çevrim içi ortamlar kullanılarak yapılan öğretmen eğitimlerinin öğretmenlerin derslerini hızlı bir şekilde geliştirmelerine katkı sağladığı, aynı zamanda çevrim içi öğretmen ağlarının hem iletişim hem de işbirlikli çalışmaları teşvik açısından etkili olduğu görülebilir. ${ }^{4}$

$\mathrm{Bu}$ süreçte kazanılan deneyimlerin değerlendirilmesi, ilerleyen dönemlerde yüz yüze eğitimde teknolojiyi daha etkili kullanmak, yüz yüze-çevrim içi bir arada harmanlanmış eğitim çalışmalarını derslerin olağan parçası haline getirmek ve acil bir durumda uzaktan eğitim-öğretime hazır olmak şeklinde üç ana doğrultuda aşağıda belirtilen hususlar gözetilerek yapılabilir.

- Altyapı eksikliklerinin giderilmesi ve kullanıcı deneyiminin geliştirilmesi açısından teknoloji entegrasyonu önemini korumaktadır (OECD, 2020).

- Çevrim içi öğrenme ortamlarının temel bileşenlerinden sayılan ve tasarımı emek ve zaman gerektiren (Yıldız ve Kartal, 2020) "sosyal varlık” ve “öğretmenin varlığı” konuları k12 öğrencilerinin sisteme dahil olmasının da etkisiyle önemini artırmıştır. Acil uzaktan eğitim-öğretim süreçlerinde öğretmenin sosyal varlığının "algılanan öneminin arttığı" ve bu sürece geçişte "öğrenci sosyal varlığının kaybı” olarak ifade edilebilecek durumlar oluşabildiği görülmektedir (Whittle, Tiwari, Yan ve Williams, 2020, s. 7). Bu bağlamda çevrim içi ders tasarımlarında öğrenmeyi geliştirebilmek için iletişim sürecinde yer alan diğer katılımcıları hissetme durumunu ifade eden "sosyal varlığı" sağlamaya yönelik grup çalışmaları vb. faaliyetlerin artırılması düşünülebilir. Öğrenmenin sosyal bir süreç olması hasebiyle fazlasıyla önem arz eden bu konuda yapılabilecekler için çevrim içi öğrenme literatürüne bakılabilir. Bu konuya ek olarak; yaşanan durumun travmatik etkileri göz önünde tutularak "ilgi, anlayış ve empati pedagojisinin ders tasarımlarında kullanılması” (Bozkurt, 2020, s. 128) üzerine düşünülebilir.

- Öğretmenin bilgi aktarıcı rolü zayıflamış, rehber, aracı, kolaylaştırıcı özellikleri daha fazla ön plana çıkmıştır. Öğrencilerin ise; "daha fazla otonomluk, kendine yetebilme ve eleştirel bakış açısını geliştirme gibi becerileri” (Bozkurt, 2020, s. 122) edinmesi ihtiyacı artmıştır. Buna bağlı olarak öğrenme sürecinde öğrencinin daha fazla rol almasını gerektiren yaklaşımların önemi artmıştır. Bu bağlamda, hem öğrencilerin kendi öğrenmelerinde daha fazla rol almalarına, hem de çevrim içi ortamlarda akranlarıla etkileşimli ve işbirliği

4 Yayınlanmamış bir araştırmanın verilerine (Yıldırım, 2020) ve bireysel gözlemlerime göre, hem hizmet içi eğitim çalışmaları hem de öğretmen ağları üzerinden geliştirilen meslektaş iletişimleri öğretmenlerin acil uzaktan eğitimöğretim sürecindeki derslerini geliştirmelerine katkı sağlamıştır. 
içinde çalışmalarına imkân veren araştırma ve proje çalışmaları, bu yaklaşımlara hizmet eden yöntemler olarak düşünülebilir.

- Ters yüz öğrenme gibi farklı modeller denenerek yüz yüze eğitimin ve çevrim içi öğrenme olanaklarının öğrenme için en uygun şekilde kullanılması/harmanlanması düşüncesi etkisini artırmıştır. ${ }^{5}$

- 21.yy. becerilerinin ve üst düzey düşünme becerilerinin geliştirilmesi gibi eğitim sisteminin disiplinler üstü ve evrensel temalarının çevrim içi ortamlarda nasıl işlenebileceğine yönelik çalışmalar yapma gereği aciliyet kazanmıştır (Şen Akbulut, 2020).

- Eksik kalan boyutlar olarak görülen içerik/materyal ${ }^{6}$ ve özellikle ölçme-değerlendirme (Bozkurt, 2020; Özer ve Suna, 2020; Shisley, 2020) alanlarına özel geliştirme çalışmalarının yapılmasına duyulan gereklilik artmıştır.

- Yüz yüze eğitime göre düzenlenmiş öğretim programlarının kazanımlar, kazanımlara ayrılan süreler, ders saatleri açısından gözden geçirilmesi ve olası tüm durumlar için A

5 Örneğin; OECD (2020), zamanın çoğunu okulda ve belli bir program dahilinde geçirmek yerine daha farklı ve esnek öğrenme modellerini düşünmeyi öneriyor.

6 Değerlendirme, her seviyede sorun olmaya devam ederken, içerik/materyal konusunda yüksek ögretimden daha çok K12'de ihtiyaç olduğu söylenebilir (OECD, 2020).

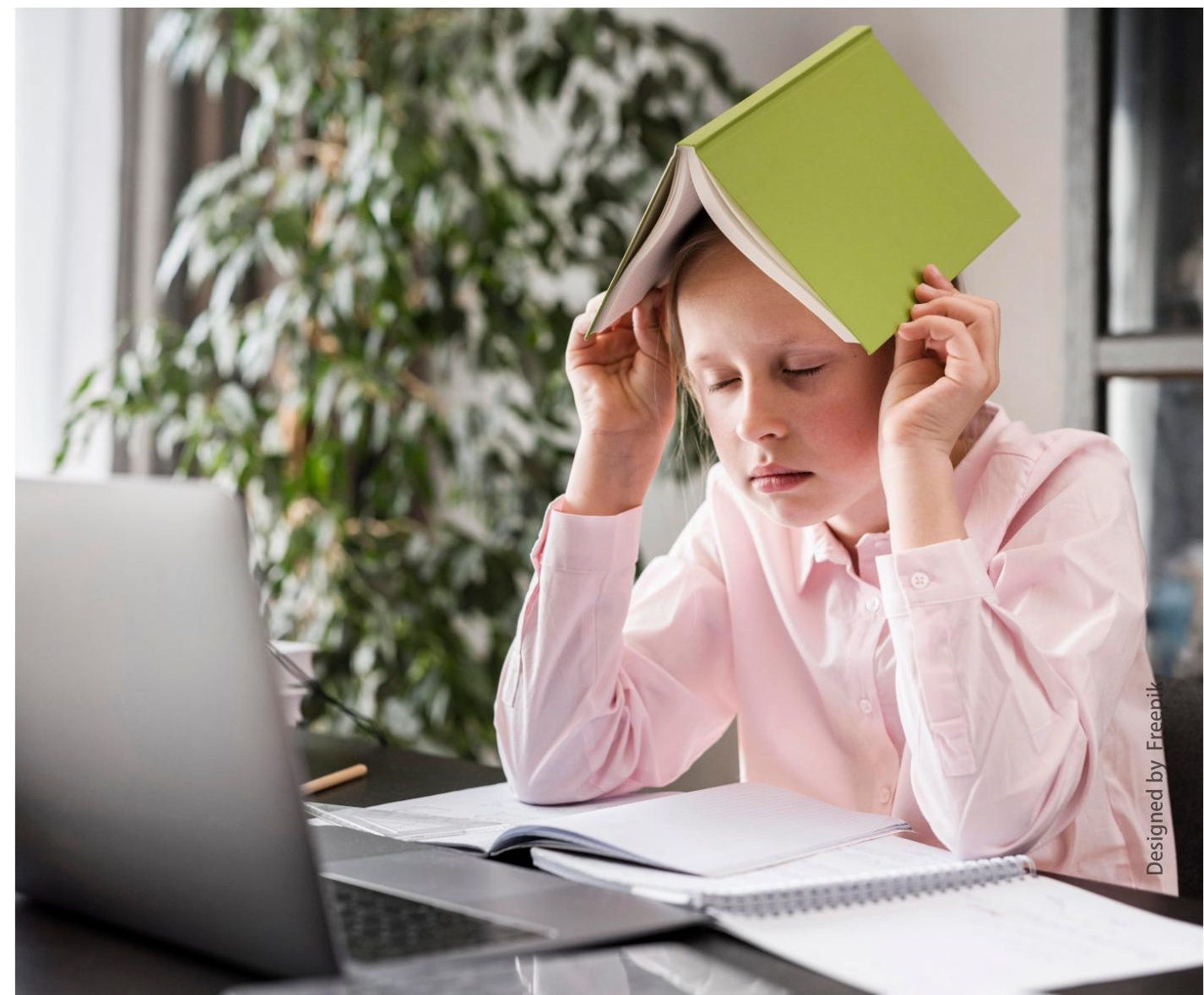


- Öğrencilerin sosyo-ekonomik farklılıklarının uzaktan eğitim-öğretimde de dezavantajlıların aleyhine sürmeye devam ettiği görülmektedir (Aguliera ve NightengaleLee 2020; Alvarez, 2020; Bozkurt, 2020; Bozkurt ve Sharma, 2020; Özer ve Suna, 2020; Van Lancker ve Parolin, 2020). $\mathrm{Bu}$ açıdan dezavantajlı gruplarda olan öğrencilerin durumunu iyileştirmeye, "dijital bölünme"yi engellemeye, etkilerini azaltmaya yönelik çalışmalar yapılması gerekmektedir. $^{8}$

- Özellikle öğrencilerin erişim durumları ve evdeki sosyal ortamları nedeniyle eğitimde eşitlik açısından tartışılması gereken yeni konular ortaya çıkmıştır (Aguliera ve Nightengale-Lee 2020; Bozkurt, 2020; Özer ve Suna, 2020; Van Lancker ve Parolin).

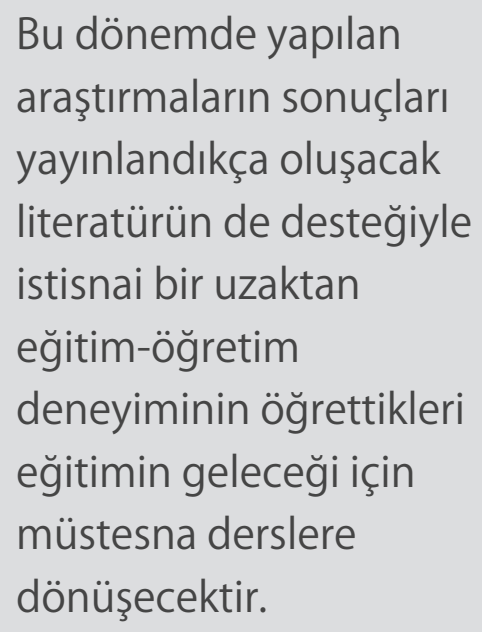

- Öğretmenlerin çalışma saatlerinde bir karmaşa ortaya çıkmış, mesai neredeyse tüm güne yayılmıştır. Öğretmenlerin çalışma şartlarının bu deneyimler gözetilerek yeniden düzenlenmesi gerekmektedir.

- Eğitimin dijitalleşmesine yönelik eleştirilerin bir boyutunu oluşturan ekran sürelerinin artmasının olumsuz sosyal ve bedensel etkilerinin nasıl tolere edileceği üzerine çalışmalar ve bunlara bağlı iyileştirmeler yapılması acil bir gereklilik olarak ortaya çıkmıştır. Uzaktan/ online eğitime yönelik özel müfredat oluşturulması ve ders saat ve sürelerinin yeniden düzenlenmesi ihtiyacının bir boyutunu da ekran süreleri meselesi oluşturmaktadır (Yıldırım, 2020).

- Acil uzaktan eğitim-öğretimin çok uzun sürmesi halinde yeni bir eğitim kültürü oluşturacağı, yüz yüze eğitimin olumlu yanları olarak görülebilecek kültürel çoğulculuk ve eleştiri-tartışma kültürü gibi özelliklerin bu durumdan zarar görebileceği gibi endişeler ortaya çıkmıştır (Agamben, 2020).

- Hem eğitim teorisi-politikasının hem de eğitim pratiğinin geliştirilmesi açısından acil uzaktan eğitim-öğretim dönemi üzerine ampirik araştırmalar yapılması ve bu araştırmaların tüm paydaşlar tarafindan incelenmesi gerekmektedir. Ayrıca döneme hâkim olan kısa vadeli, çözüm odaklı yaklaşımların etkinliğini denetleyebilmek ve uzun erimli bir anlayış geliştirebilmek için eğitim felsefesine yönelik tartışmalar yürütme ihtiyacı ortaya çıkmıştır.

8 Örneğin; bu durumdaki öğrenciler için dizüstü bilgisayar temini öneriler arasında yer almıştır (OECD, 2020; Yılmaz, 2020). 
$\mathrm{Bu}$ hususlar, öğretmenlerin ve eğitim araştırmacılarının acil uzaktan eğitim-öğretim dönemindeki deneyim ve gözlemlerinden faydalanılarak imkânı bulunabildiği ölçüde literatürle ve önceki deneyimlerle kıyaslanarak belirlenmiştir. Eğitimin ilerleyen dönemlerde nasıl bir hâl alacağı konusunda net tahminlerin yapılamadığı bir zamanda bu çıkarsamalar -süreci yaşayan herkesin farklı katkılarıyla birlikte- baz alınarak muhtemel durumlara yönelik hazırlık yapılabilir. Bu dönemde yapılan araştırmaların sonuçları yayınlandıkça oluşacak literatürün de desteğiyle istisnai bir uzaktan eğitim-öğretim deneyiminin öğrettikleri eğitimin geleceği için müstesna derslere dönüşecektir.

* Değerlendirme ve önerileriyle yazının gelişmesine katkı yapan Ayşe Arıkan, Diler Dilaver Türe, Kader Koç ve Hatice Varlik'a teşekkür ederim.

\section{Kaynakça:}

Agamben, G. (2020). Öğrencilere ağıt. (K. Cenk, Çev.) https://uni-versus.org/2020/05/23/agambenkoronavirus-ogrencilere-agit/ adresinden 04.08.2020 tarihinde alınmıştır.

Aguliera, E. \& Nightengale-Lee, B. (2020). Emergency remote teaching across urban and rural contexts: perspectives on educational equity. Information and Learning Sciences, 121(5/6), 471-478. https:// doi.org/10.1108/ILS-04-2020-0100

Alvarez, A. Jr. (2020). The phenomenon of learning at a distance through emergency remote teaching amidst the pandemic crisis. Asian Journal of Distance Education, 15(1), 144-153. https://doi. org/10.5281/zenodo.3881529

Bozkurt, A. (2020). Koronavirüs (Covid-19) pandemi süreci ve pandemi sonrası dünyada eğitime yönelik değerlendirmeler: Yeni normal ve yeni eğitim paradigması. AUAd, 6(3), 112-142.

Bozkurt, A., \& Sharma, R. C. (2020). Emergency remote teaching in a time of global crisis due to CoronaVirus pandemic. Asian Journal of Distance Education, 15(1), i-vi. https://doi.org/10.5281/ zenodo. 3778083

Cai, R. \& Wang, Q. (2020). A six-step online teaching method based on protocol-guided learning during the COVID-19 epidemic: A case study of the first middle school teaching practice in Changyuan City. Henan Province, China. SSRN. https://ssrn.com/abstract=3555526 http://dx.doi.org/10.2139/ ssrn. 3555526

Durdu, L. ve Onay Durdu, P. (2013). Çevrimiçi öğrenme ortamları. K. Çağıltay ve Y. Göktaş (Ed.), Öğretim teknolojilerinin temelleri: Teoriler, araştırmalar, eğilimler içinde (ss. 534-552). Ankara: Pegem Akademi Yayınları.

Golden, C. (2020). Remote teaching: The glass half-full. Educause Review. https://er.educause.edu/ blogs $/ 2020 / 3 /$ remote-teaching-the-glass-half-full

Hodges, C., Moore, S., Lockee, B., Trust, T., \& Bond, A. (2020). The difference between emergency remote teaching and online learning. Educause Review. https://er.educause.edu/articles/2020/3/thedifference-between-emergency-remote-teaching-and-online-learning

Means, B., Toyama, Y., Murphy, R., Bakia, M., \& Jones, K. (2010). Evaluation of evidence-based practices in online learning: A meta analysis and review of online learning studies. Washington DC: US Department of Education.

OECD (2020). Education responses to COVID-19: Embracing digital learning and online collaboration. OECD Policy Responses to Coronavirus (COVID-19). http://www.oecd.org/coronavirus/ policy-responses/education-responses-to-covid-19-embracing-digital-learning-and-onlinecollaboration-d75eb0e8/ 
Özer, M. ve Suna, H. E. (2020). Covid-19 salgını ve eğitim. M. Şeker, A. Özer ve C. Korkut, (Ed.), Küresel toplumun anatomisi: İnsan ve toplumun geleceği içinde (s. 171-192). Ankara: Türkiye Bilimler Akademisi - TÜBA.

Shisley, S. (2020). Emergency remote learning compared to online learning. Learning Solutions. https:// learningsolutionsmag.com/articles/emergency-remote-learning-compared-to-online-learning

Simonson, M., Smaldino S. \& Zvacek, S. M. (2015). Teaching and learning at a distance: Foundations of distance education, 6th Edition, Revised ed. Edition. Charlotte: Information Age Publishing, Inc.

Stern, J. (t.y.). Introduction to online teaching and learning. http://www.wlac.edu/online/documents/otl.pdf adresinden 04.08.2020 tarihinde alınmıştır.

Şen Akbulut, M. (2020). Dijital teknolojilerin eğitimde etkin kullanımı. Bilim ve Teknik, 53(631), 48-55.

T4 Teacher Manifesto (2020). Teachers at the heart of decision making: A Manifesto for Teachers. T4. https://www.t4event.one/onewebmedia/T4\%20Takeaways\%20-\%20Teachers\%20at\%20the\%20 heart\%20of\%20decision\%20making\%20\%28a\%29.pdf

Van Lancker, W. \& Parolin, Z. (2020). COVID-19, school closures, and child poverty: a social crisis in the making, Lancet Public Health, 5(5), 243-244. https://doi.org/10.1016/S2468-2667(20)30084-0

Whittle, C., Tiwari, S., Yan, S. and Williams, J. (2020). Emergency remote teaching environment: A conceptual framework for responsive online teaching in crises. Information and Learning Sciences, 121(5/6), 311-319. https://doi.org/10.1108/ILS-04-2020-0099

Yen, T.-F. (TF). (2020). The performance of online teaching for flipped classroom based on COVID-19 aspect. Asian Journal of Education and Social Studies, 8(3), 57-64. https://www.journalajess.com/ index.php/AJESS/article/view/30229

Yıldıım, K. (2020). [Covid-19 Uzaktan eğitim-öğretim dönemi değerlendirmesi]. Yayınlanmamış ham veri.

Yıldız, S. ve Kartal, G. (2020). Uzaktan eğitim - Acil! https://sarkac.org/2020/06/uzaktan-egitim-acil/ adresinden 04.08.2020 tarihinde alınmışırı.

Yılmaz M. (2020). Uzaktan eğitimin iyileştirilmesi: Salgın kaynaklı eğitim krizini aşmak için öneriler (Politika Notu: 2020/12). İstanbul: İLKE İlim Kültür Eğitim Vakfı. 
